\title{
Lying, or Storytelling, as Antidote to Unhappiness in Robin Klein's Hating Alison Ashley and Anne Fine's $A$ Pack of Lies and Goggle-eyes
}

\author{
Alice Curry
}

Lying and poetry are arts - arts, as Plato saw, not unconnected with each other - and they require the most careful study, the most disinterested devotion.

- Oscar Wilde, The Decay of Lying

A great man - a man whom nature has constructed and invented in the grand style - what is he? ... He rather lies than tells the truth; it requires more spirit and will.

- Nietzsche, Will to Power

Wilde and Nietzsche posit lying as an artistic form of self-expression, done knowingly, purposefully and with attention given to form and detail. Lying frees the liar from the constraints of truth, moving him or her into the higher realms of deliberately-conceived art and away from the grim realities of unpolished nature. In Robin Klein's Hating Alison Ashley (1984) and Anne Fine's Goggle-eyes (1989), this grim reality comes in the form of the introduction of an alien element into the young protagonists' families: the boyfriend, and potential husband, of their mother. For both Erica and Kitty, lying, spinning a good yarn or telling tales constitutes their chosen way of mitigating the unhappiness that results from this unwanted addition to their families. Storytelling allows the girls to create a space within which to negotiate their relationships with their soon-to-be extended family, and ultimately integrate into the family circle the person whom they feel has threatened the stability of their family. This space for negotiation is humorous, and takes the form of an imaginatively constructed alternative or exaggerated reality: a space of liberating make-believe, in which the girls can distance, and de-familiarise, themselves from the truth of their situations. I am drawing here on the account of 'make-believe' offered by Eric Prenowitz:

Make-believe is not a mode of measured philosophical enquiry. It is not for real, only a game. Something children do, for the fun of it. Readers likewise, and theatergoers. It engages knowingly in untruth and a certain artificial reality. One never makes believe unintentionally or by mistake. It therefore supposes a conscious, self-present, responsible subject-but only to divide itself, to absent itself, without any possible response, from itself.

(2006, p.148)
By creating stories or constructing lies, Erica and Kitty become honorary authors, gaining in self-confidence and subjectivity through increased possibility for selfexpression. Lying becomes an art form, allowing the girls to take life and deliberately and thoughtfully reproduce it as story. Both texts, then, are inherently metafictional: Erica and Kitty replicate the storytelling processes of Klein and Fine, creating a microcosm of aesthetically-pleasing stories and clever lies. The girls' reactions to unhappiness in this text, call attention to, and make use of, the fictionality of the constructed text, and in so doing, highlight the creative and therapeutic impulse behind storytelling as an art form.

Anne Fine had earlier explored the issue of lying and storytelling in A Pack of Liars (1988), which is practically a thesis on lying and offers an informative grounding for comment on the two novels which are the focus of this paper. As a dialogic debate about the rights and wrongs of lying, which is presented as the most morally-suspect form of storytelling, this early novel is a direct precedent for Goggle-eyes and parallels Hating Alison Ashley in several ways. Whilst $A$ Pack of Liars condemns lying as an unhealthy tendency in children which should be eradicated as quickly as possible, in its detailing of the illicit pleasures of lying and the artistic freedom that naturally comes to the liar, this novel at the same time suggests that lying not only inspires creativity, but also enhances subjectivity and self-confidence. This implicit message, grating against the overt moralistic stance of the novel as a whole, provides a model of interpretation for both Goggle-eyes and Hating Alison Ashley, following Plato, Wilde and Nietzsche in its (perhaps unwitting) exposure of the liberating effects of creative lying.

The novel begins with a classroom assignment to write letters to a penpal in a neighbouring town. Oliver is given a penpal who is surprisingly honest and open in his letters yet admits to sometimes telling 'terrible lies' (p.39). Laura, on the other hand, although scrupulously honest in general life, decides that her penpal is so dull that she will liven up the assignment by writing an elaborately-conceived and entirely fictional letter signed by the imagined 'Lady Melody Estelle Priscilla Hermione Irwin'. Whilst Laura can see no harm in playing a 'joke' (p.20) like this, Oliver reacts quite differently: 
"You've told a pack of lies!"

His shock was evident. He was scandalised.

"It's just one terrible lie after another. It's nothing to do with the truth.

What have you done?"

(p.20)

We are very quickly, then, presented with three different philosophies on lying: Simon, Oliver's penpal, tells lies in order to mitigate his unhappiness at home and at school even though he knows his lies may do more harm than good; Laura tells lies in her letter simply to create a good story and as a 'joke' without meaning any harm; Oliver never tells lies and believes that lying is wrong, with no exceptions. These differing philosophies, ranging from one extreme to the other, are pitted against each other as the novel progresses, with the most attention given to Laura's middle philosophy, the grey area where lying is viewed as harmless. The novel asks the question whether there is such a thing as a 'harmless' lie or, put another way, a lie without consequences?

In Simon Huggett we have a character who tells lies in order to distract himself from feeling miserable: to forget that he does not get along with his parents and has no friends at school. Instead he creates a glamorous and exciting life for himself through storytelling:

[I] told her my mother wasn't really my mother at all because I am a long lost, secret son of Prince Charles, and my mum and dad just pretend I am theirs to save the Queen and the Queen Mother from unbearable embarrassment.

(p.40)

Laura and Oliver are shocked by Simon's behaviour and in a very self-righteous manner determine to reform him, forcing him to give up not only lying but all of his bad habits (which include twitching, fidgeting, chewing and biting his nails). In the eyes of both Laura and Oliver, lying of Simon's sort is definitely wrong, and so runs the philosophy of the novel as a whole. In fact, when the novel ends, Simon is a completely reformed character, and we are meant to believe that his life will be better for the change. In Laura's smug and self-satisfied words:
'She'd pulled his socks up for him a good three quarters of the way' (p.101).

Lying of a different and more problematic kind comes in the collective penpals' letters to the children in Laura's class, for the letters are not from a group of twenty school children as assumed, but from one man whose intention is to gain information about his chosen victims' living arrangements: the size and layout of their houses, the number of valuable items in each room, the usual times at which the families go out and leave the houses empty and so on, so that he can burgle them. Yet, the profits from the burglaries do not go to the thief but to charity, making him 'a sort of modern Robin Hood' (p.82). Laura and Oliver debate whether this form of lying could be justifiable, but quickly decide that, whatever the cause, it cannot be right for:

Lies go hand-in-glove with other forms of wrongdoing, don't they? You don't need lies to shore up honesty and fairness... The people who depend on lies to get by are people like murderers and cheats and thieves...

(p.69)

This overly dramatic conclusion suggests that lying of this form, even if it is for an honorable cause, is also wrong, and the novel as a whole is quick to hammer this point home with a contrite letter from the burglar near the end of the novel, renouncing his wicked ways: 'What I was doing was dangerous and foolish, and I'm so glad you forced me to stop before I got into the most terrible trouble' (p.118).

Attention is turned, therefore, to Laura's white lies: her created character Lady Melody and her constructed life, and the question whether 'jokes' like this one are in fact as harmless as they seem. The consistent focus on the guilt Laura feels after telling lies to Miranda and Oliver's maxim that 'If we start lying, too, there'll be more lies about, won't there? And the more lies there are about, the less everyone in the world is going to be able to trust one another' (p.94) suggests that lying, even when it is believed to cause no harm, is still morally wrong. Yet the most intriguing effect of Laura's lying is the growing self-confidence and creativity that it brings her. In deciding to take the penname Lady Melody, Laura is described as becoming 'lost' in the 
creative moment (p.12). A 'smile spread[s] over her face' (p.12), she stops feeling cramp in her hand and the time flies by as she writes. When finished, she feels 'quite proud' (p.20). The inspiration for Laura's stories is described as something coming not from within, but from outside of her, almost without her consent: 'It wasn't really Laura's fault that another example immediately sprang to mind' (p.23). This divinely-inspired storytelling, then, comes naturally to Laura and so, therefore, does lying, as is shown by her several creative and humorous attempts to persuade Oliver that lying is not always wrong:

"Suppose a man frothing at the mouth and carrying a blood-stained hatchet forced his way into the playground and wanted to know which way Mrs Coverley had gone. You wouldn't tell him she'djust gone in the staff lavatories, would you? You'd say she'd gone home with a terrible headache."

(p.23).

Storytelling gives the normally 'shy' and 'sensitive' Laura a new-found confidence and self-awareness, allowing her to channel her creativity into her imaginative and eloquent letters to Miranda (p.8).

Laura's letter-writing is interspersed with a metafictive focus on the imaginative process and the nature of storytelling itself. Paragraphs of her letters are juxtaposed with sentences judging the lines that have just been written or debating how to continue:

'That's that, thought Laura, cheering up fast. Not only is it brilliant, but it helps with the next bit'; 'Sold what? Think back! She mustn't forget anything'; 'Press on quickly, before Miranda had time to become suspicious'; 'Right. That was that sorted out. Back to the father'

(pp.47-50).

As the letter writing continues, we can watch Laura's selfconfidence increasing even whilst her tall tales get taller. Storytelling, then, provides Laura with an imaginative and humorous space within which to forget her 'tongue-tied' and 'nervous' self, and truly come out of her shell (p.111). This can be seen quite clearly in her use of linguistic exaggeration and melodrama in her penultimate letter to the thief: 'Who did I see? You! In your thief's den with your ill-gotten gains! A barefaced robber! ... How dare you? How dare you? You are a thief, a liar and a cheat!' (p.89). Here we would barely recognise the 'sensitive plant' that we are told Laura used to be (p.8). At the end of the novel, Laura's ability to stand up in front of the class and suggest the next school project clearly implies that the storytelling/lying experience has on the whole benefited her as a person and taught her valuable life lessons.

If lying, then, is wrong on all accounts, it sits in uneasy juxtaposition with the creativity and self-confidence that storytelling brings. It is this latter potential for growth in imagination and understanding through storytelling that Anne Fine takes forward to her next novel, Goggle-eyes, and which Robin Klein likewise makes use of in Hating Alison Ashley. Both Erica and Kitty, like Simon, lie or tell stories in order to mitigate the unhappiness of their home lives: unhappiness gives both girls an excuse to take action against those who they believe are to blame for their situation. This action is often self-indulgent or absurd, yet through lying or telling tales both girls gain the space within which to distance themselves from their unhappiness and in so doing gain also in self-confidence and understanding, to the point at which they can see the error of their ways and deal with their changing home lives in a more adult and sensible manner. As in A Pack of Liars, storytelling, although dubious in its implications, finally allows the protagonists to accept the situations in which they find themselves and find a creative and entertaining solution to the problem of unhappiness, transforming that which is painful or makes them unhappy into something safe, productive and empowering. This is achieved through a variety of comic distancing and defamiliarisation techniques.

Like any good storyteller, Erica and Kitty have a penchant for the dramatic, and both Hating Alison Ashley and Goggleeyes make use of the comic technique of exaggeration at a linguistic level. Whilst Erica can repeat the melodramatic line 'I wish I were dead!' five times, 'each time stressing a different word and listening to the result' (p.36), Kitty can give Gerald a look that 'would have shrivelled Rasputin' and turn on him 'the evil eye' (p.63). In the context, this exaggeration is humorous for it drains the words of all original meaning and deflects any sympathy 
the reader might have for the girls. Erica's and Kitty's fondness for drama, then, means that their solutions to their unhappiness are often distanced from the truth of the situation, an example being Kitty's essay on 'Something I Hate' which, as a grotesque caricature of 'Goggle-eyes,' pushes the usually patient Gerald too far and, even in Kitty's estimation, borders on being 'rude,' and full of 'spite' (p.47). Drama, then, is viewed as one solution to the problem of unhappiness, yet often functions in an uneasy dialogue with the more realistic, everyday adult world in which the families of the girls are living.

As the comic use of drama suggests, unhappiness often adds a performative element to the texts. For both girls, unhappiness manifests itself in a humorous externalising of their internal, emotional struggles. Erica's desire to be a glamorous actress prefigures this fondness for performance, and allows her to stand back and watch as she exhibits her unhappiness: 'The part of me that wanted to be an actress stood aside and looked on whilst I was bawling'. Kitty also enjoys seeing her mother's pantomimic performance when she deplores the decline of the municipal library, as it allows her to 'raise [her] eyes to heaven' and participate in 'a really silly scene', 'scene' being an apt word to use in this context as it originates in stage production (p.69, 70). By externalising their emotions in this way, both Erica and Kitty can defamiliarise their own feelings of unhappiness. This externalising of emotions also allows the reader to visualise the otherwise hidden internal struggles of the girls from a safe and neutral vantage point. We can find the girls' behaviour comic because we laugh not at their emotional struggles but at the exaggerated and objectified projection of these struggles. Erica, in fact, clearly demonstrates that humour can arise from unhappiness in her ability to 'enjoy' crying: 'I always enjoyed having a good cry' (p.36). By enjoying an action which we culturally assume to signify deep unhappiness, Erica signals that unhappiness, in this text, should be read as concomitant with comedy, and only superficially, if at all, worthy of the reader's sympathy.

In laughing at Erica's and Kitty's often ridiculous responses to unhappiness, the reader is solicited to become complicit in their actions. Both texts are demonstrative in their attitude towards the reader. At various points throughout the novels, Erica and Kitty appeal to the reader to acknowledge their point of view. In Goggle-eyes, in the chapter in which Gerald fixes the radiator in her room, Kitty speaks directly to the reader, or listener in the case of Helen: " "I think you mentioned an air lock in our pipes," I said coldly. Notice that? Not the pipes. Our pipes'. By telling her story after the events have taken place, Kitty can draw attention to the literary construction of her tale with an irony made possible through hindsight, making her story both metafictive and self-reflexive. In analysing her behaviour, Kitty is aware of the absurdity of her past actions: 'And I annoyed him, I know I did. I was a little turd, to tell the truth' (p.45). She knows that the complicity of the reader must be earned rather than assumed.

Erica, however, is far less self-aware. When she details a list of items cluttering up the kitchen table, the narrative strategy of telling rather than showing implies that Erica has complete confidence that the reader will take her side: 'I cleared a space on the kitchen table to mix up some lemon cordial. This is what I had to clear away...' (p.53). No analysis of the implications of the mess is given; Erica is confident that the simple mention of the household items will be enough to elicit sympathy on her behalf. Comedy, here, comes in the fact that, unlike Kitty, Erica has no notion that her responses to unhappiness are absurd and self-serving, and we laugh at her lack of self-awareness, as in the following passage:

“[H]aving someone with experience will make our
photography programme more interesting," said
Miss Lattimore. "Especially for the members of
this class who already think they know it all and
can't be taught any more by anyone." (Naturally
she meant Barry Hollis, although she was looking
in my direction...)
(p.43).

Here, it is Erica's blatant self-deception that has potential for encouraging feelings of knowing superiority in the reader, and possibly laughter. Erica's narratorial confidence parallels both girls' confidence in their ability to interpret the actions of others. In both novels, the girls believe they have a privileged insight into their friends' and families' hidden thoughts and agendas. In Hating Alison Ashley, Erica is sure that Alison's innocence is a façade: 'She was inspecting the Barringa East mums with her 
innocent expression to which only I knew the code'; in Goggle-eyes, Kitty views Gerald as someone whose looks are deceiving: 'Mum ... might have believed that he was just being pleasant. But I was pretty sure that I could hear a message underneath' (p.37). Here, humour arises from the irony inherent in this ostensibly perceptive analysis of Alison's behaviour and Gerald's words. The use of the words 'code' and 'message' suggests that Erica and Kitty believe themselves to be privy to the 'truth' behind the false exteriors, whilst we can see that in both cases there is no basis for this judgment: Alison's 'innocent expression' most likely does signal her innocence, and Gerald probably is 'just being pleasant'. The fallibility of the narrators provides humour in the discrepancy between the protagonists' often absurd interpretations that readers can plainly see for themselves.

These several distancing or defamiliarising techniques, whereby the protagonists distract themselves from their unhappiness by finding creative, yet superficial, ways in which to react against adult authority, all point to the girls' most effective solution in the struggle against unhappiness: their ability to turn their lives into a story. By repositioning themselves as characters in a story, Erica and Kitty, like Laura in A Pack of Liars, objectify their experiences and give themselves the space within which to negotiate, and interpret, the events that befall them; in a sense, both girls defamiliarise themselves through storytelling, in order to look upon their experiences with fresh eyes. Telling stories is a safe way to escape from that which scares and worries them, allowing for the possibility of an alternative reality in which the young protagonists have more than just limited agency. Unhappiness manifests itself in creativity. This can clearly be seen in both novels in the way in which Erica and Kitty repeatedly fit the alien elements in their family into their own imagined scenarios:

\section{I considered various ways I could explain Lennie. I could saymum was a psychiatrist and Lennie one of her patients. Or that he was our gardener...Could I say Lennie was my grandfather? She'd never believe that, because he didn't look quite old enough...}

(Klein, p.60)

\begin{abstract}
[I would lie] awake in bed imagining all those dire accidents in which I made him the star, night after night. On Monday I'd arrange for a huge industrial smokestack to topple on his head. On Tuesday he'd succumb to a grisly and incurable disease. Some drunk driver might run him over on Wednesday...
\end{abstract}

(Fine, p.44).

Unhappiness nurtures in the protagonists a creative desire to shape their surroundings to their own benefit. As Erica suggests, lying or telling tales is simply a case of 'decorating statements to make them sound more interesting'; through lying, Erica can quite literally turn her life into a fairy tale.

This creativity constitutes an effort to gain control of a situation over which the girls otherwise have no say: their mothers' relationships. In Erica's and Kitty's imaginings, Lennie and Gerald are subject to their whims and function within their own constructed realities. Fitting Lennie and Gerald into a story that has nothing to do with the protagonists' home lives contains and neutralises the threat they pose to the stability of the girls' families. As Kitty says of Mrs. Lupey's thoughts on storytelling, telling stories helps make the 'long and doggy business' of life more bearable: 'Some [stories] help you with the living itself. Some help you just take a break. The best do both at the same time' (p.165). Imagining situations in which the alien elements in the household are made to sound glamorous and enticing, or killed off, constitutes a way for the girls to 'take a break' from their unhappiness, and provides much comedy for the reader. As Roderick McGillis suggests of storytelling in general: 'Stories have traditionally been one of the sources of social construction, one of the means by which a culture perpetuates itself and situates itself over against an "other" culture' (1997: p.216). Here, the 'other' culture is that of the parental generation: those whom Erica and Kitty blame for their unhappiness. Telling lies and stories as a way of taking a stance against this alien generation not only distracts the girls from their problems at home, but also gives them the same confidence that Laura felt in A Pack of Liars. Kitty repeatedly discusses her storytelling abilities in a self-congratulatory tone: 'Whoops! Wrapped up entirely 
in my own brilliant storytelling, I'd totally forgotten this was her problem too' (p.78).

In all their efforts to construct lies or tell stories, there is the suggestion that, ultimately, the girls are simply trying to find the right words with which to express their feelings of unhappiness to the people who may be able to help them regain that happiness: their mothers. Both girls try out various modes of communication before they find one which truly, rather than superficially, mitigates their unhappiness. In Hating Alison Ashley, Erica consistently attempts to think of 'good line[s]' and 'powerful statement[s]' with which to express her feelings: 'I thought of another good line..."Just one more mile for to tote the weary lode," I said, and it sounded beautiful, though very sad and depressing' (p.36). Kitty similarly attempts to express her unhappiness through literary formulas: she writes 'odes', 'descriptive essays' and 'Sixteenth-century limericks' all with a focus on her hatred for Gerald:

\section{I kept handing in my little masterpieces at school: my "Ode to An Unwelcome Guest," my notes for a class talk entitled "Divorce Should Be Forbidden Until the Last Child Has Left Home, " mydescriptive essay called "An Old Man Ageing"}

(Fine, p.48).

Ultimately, it seems, elegant literary paradigms or the melodramatic phrases of acting are insufficient to express the individual and personal feelings of the girls. And it is here that both Hating Alison Ashley and Goggle-eyes go one step further than A Pack of Liars. In Fine's earlier novel, Laura decides not to disclose to the thief that she is not in fact Lady Melody, having gained much if not all of her new-found confidence by taking on the characteristics of this fictional persona. Without this alter ego, it would seem, Laura must remain, to all intents and purposes, the 'sensitive plant' that she was to begin with. At the end of the novel, in a humorous about-turn by Oliver, truth-telling becomes just 'some tiny little principle' (p.119) and both protagonists are happy to leave the thief in the dark about Laura's true identity. This is not so for Erica and Kitty, however, who realise that they must set aside their clever literary attempts and assumed personas and instead use their own words to express their personal and private feelings about their unhappiness at home.

Consequently, Kitty only begins to believe that she might be able to accept Gerald into the family when he adopts her point of view and her words, thereby denoting his fellow feeling: 'Now that was definitely my line. If I've said that once, I've said it well over a thousand times...I was left speechless, honestly I was'(p.132; p.133). Kitty's speechlessness signals her acknowledgement that her superficial, overly dramatic and often cruel attempts to keep Gerald at a distance have so far been entirely ineffectual. It is this realisation that prompts Kitty to think: 'if I could only understand, I might be able to get along with him better' (p.136). As John Stephens suggests, 'Fine's narrative strategy... simulates character development by simultaneously disclosing the 'real' Gerald and bestowing on Kitty sufficient growth in understanding to recognise both Gerald's qualities and her own changed feelings towards him' (1998, p.27). With this change of feeling, Kitty is finally able to appreciate the value of her own words in expressing her feelings, so that, ultimately, she will be able to tell the most productive story of all: the story of her own struggles to accept Gerald into the family told to Helen in order that Helen will be able to accept 'Toad-shoes' into hers.

Erica's similar change of feelings towards Lennie comes in the context of the plays she has written, using her own words. In accepting Lennie's help and opening up to him about her fears that the plays are not well written, or that her own words are not sufficient, Erica allows herself to begin caring for the man whom she had originally blamed for her unhappiness. In the success of the plays, Erica gains in confidence and agency, realising not only that her own words are the best way of expressing herself, but also that she is lucky to have a family like hers: 'I ached with gratitude that I was me, and not Alison Ashley, whose mother hadn't bothered to turn up at all' (p.176). It is this gratitude that enables her, like Kitty, to begin constructing stories for the benefit of others, rather than for herself; through constructing one final lie, she keeps the reason why Alison's mother was not at the play a secret: "'Mrs Ashley isn't here tonight... She's an air-traffic-control technician, and airports can't close down just because 
there's a concert on"' (p.178). Through playwriting, then, as an alternative, and more productive, form of storytelling, Erica gains not only a happy family but also a best friend in Alison Ashley.

The unhappiness of the central protagonists has all but disappeared by the end of the novels, and the alien elements of the household have been successfully integrated into the family. Unhappiness, therefore, functions as the emotional force behind the struggles of Kitty, Erica, by association Alison Ashley, and by implication all children coping with the divorce of their parents. In the comic handling of unhappiness, the authors suggest that there is always the possibility of a positive outcome to these struggles, and adult-child relationships that are without strain. Yet outcomes such as these are only positive because they signal a truce in the young protagonists' rebellion against adult authority, and a form of closure which ultimately establishes the ideological premise that adults know best and children have little power for subversion. In this rather conventional teleology, lying, or storytelling, is the one thing which allows both girls, like Laura in A Pack of Liars, the freedom to imagine a world in which they themselves have more than just limited agency, giving them the ability to find their own creative solutions to the problem of unhappiness.

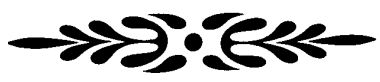

\section{REFERENCES}

Fine, Anne (1990) A Pack of Liars. London, Puffin Books.

(1989) Goggle-eyes. Boston, Little, Brown and Company.

Klein, Robin (1984) Hating Alison Ashley. Ringwood, Penguin Books Australia.
McGillis, Roderick (1997) 'Self, Other, and Other Self: Recognizing the Other in Children's Literature', The Lion and the Unicorn 21, 2: 215-229.

Nietzsche, Friedrich (1968) Will to Power. London, Vintage.

Prenowitz, Eric (2006) 'Make Believe: Manhattan's Folittérature', New Literary History 37, 1: 147-167

Stephens, John (1998) 'Ideologie und Narrativer Diskurs in Kinderbüchern', in Hans-Heino Ewers et al. (eds.) Kinder- und Jugendliteratur Forschung 1997/98. Stuttgart, Verlag J. B. Metzler, pp. 19-31. ["Fines Erzählstrategie inszeniert Characterentwicklung, indem sie den "wahren" Gerald zum Vorschein kommen läßt und gleichzeitig Kitty so viel an Reifung zubilligt, daß sie sowohl Geralds Qualitäten erkennt als auch den Wandel ihrer eigenen Gefühle ihm gegenüber.']. Translated from English by Reinbert Tabbert.

Wilde, Oscar (2004) The Decay of Lying. Montana, Kessinger.

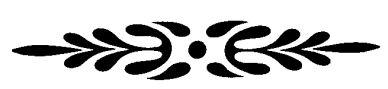

\section{BIOGRAPHICAL NOTE}

Alice Curry gained her BA from Oxford University and an MA in Children's Literature from Macquarie University. Her interests are in fairy tale, cross-cultural studies and the use of heterotopic space within children's fiction. 